\title{
Increasing viscosity of the intestinal contents alters small intestinal structure and intestinal growth, and stimulates proliferation of enterotoxigenic Escherichia coli in newly-weaned pigs
}

\author{
D. E. McDonald ${ }^{1}$, D. W. Pethick ${ }^{1}$, B. P. Mullan ${ }^{2}$ and D. J. Hampson ${ }^{1}$ \\ ${ }^{1}$ Division of Veterinary and Biomedical Sciences, Murdoch University, Murdoch, Western Australia 6150, Australia \\ ${ }^{2}$ Agriculture WA, Baron-Hay Court, South Perth, Western Australia, Australia
}

(Received 2 October 2000 - Revised 20 April 2001 - Accepted 7 May 2001)

\begin{abstract}
Sources of viscous soluble fibre, such as barley and oats, have often been included in the weaning diet of the pig to accelerate development of the large intestine. Inclusion of a non-fermentable, viscous compound, sodium carboxymethylcellulose (CMC), in a low-fibre weaning diet was tested to assess the influence of digesta viscosity on the gut in the absence of increased fermentation. Two CMC sources, of low and high viscosity, were added to cooked rice-based diet at $40 \mathrm{~g} / \mathrm{kg}$ total diet. A third control rice diet did not contain any CMC. Diets were fed for $13 \mathrm{~d}$ following weaning at 3 weeks of age. Addition of $\mathrm{CMC}$ to the diet significantly increased the intestinal viscosity of digesta within the small $(P<0.001)$ and large $(P<0.05)$ intestine. No simple association was found between increases in intestinal viscosity and effects on intestinal morphology and whole-body growth. The average empty-body-weight gain and the small intestinal villus height increased with low-viscosity $\mathrm{CMC}$, but decreased with the high-viscosity CMC group. The full large intestinal weight increased in all pigs fed CMC. Dietary CMC (both low- and high-viscosity) increased the percentage moisture of digesta and faeces, and was associated with increased faecal shedding of enterotoxigenic haemolytic Escherichia coli. Feed ingredients in weaning diets that excessively increase the viscosity of the intestinal digesta may be detrimental to pig health and production.
\end{abstract}

Intestinal adaptation: Viscosity: Carboxymethylcellulose: Escherichia coli: Pig

There is increasing evidence that viscous dietary soluble NSP can interfere with nutrient digestion and absorption in single-stomached animals, although consequences differ between species. In poultry, addition of cereals containing high amounts of viscous soluble NSP to the diet depresses nutrient utilisation within the small intestine, reduces weight gain and can increase the incidence of wet, sticky droppings (Choct \& Annison, 1992). The anti-nutritive effects of viscous soluble NSP in poultry have been linked primarily to increased viscosity of digesta within the small intestine. Increased intestinal viscosity is caused by the presence of soluble NSP, and the association with antinutritive effects is supported by the removal of detrimental effects through addition of exogenous enzymes that reduce viscosity by partial hydrolysis of the soluble NSP (Burnett, 1966; Campbell et al. 1989; Bedford \& Classen, 1992; Choct \& Annison, 1992; Choct et al. 1996).

A similar interference with nutrient absorption has been noted in pigs fed synthetic viscous NSP such as guar gum
(Rainbird et al. 1984; Rainbird, 1986; Rainbird \& Low, 1986b; Ellis et al. 1991, 1995; Ehrlein \& Stockmann, $1998 a, b)$. Increasing intestinal viscosity in pigs can decrease absorption of glucose (Rainbird et al. 1984) and other nutrients (Ehrlein \& Stockmann, 1998b) as well as altering the force and frequency of peristaltic contractions (Cherbut et al. 1990). Although these studies were carried out in grower pigs (weighing about $40 \mathrm{~kg}$ ) used as biomedical models, there is evidence that viscous soluble dietary NSP also may have detrimental effects in the small intestine of weaner pigs (McDonald et al. 1999). Increased intestinal viscosity is more likely to have an impact on weaner pigs than older pigs, as the physical capacity and therefore the dilution of viscosity by intestinal secretions is less in newly-weaned pigs.

The anti-nutritive effects of soluble NSP in poultry feeds also can be partially alleviated by feeding antibiotics, especially when the soluble NSP are from rye, which suggests that gastrointestinal microflora play a major role in

\footnotetext{
Abbreviations: CMC, carboxymethylcellulose; PWC, post-weaning colibacillosis; VFA, volatile fatty acid.

* Corresponding author: Dr Deborah E. McDonald, fax + 6189310 4144, email debmcdon@numbat.murdoch.edu.au
} 
the anti-nutritional influence (MacAuliffe \& McGinnis, 1971; Misir \& Marquardt, 1978; Antonious \& Marquardt, 1982). Recent studies have shown a complex interaction among the microflora of the gut, intestinal viscosity and dietary soluble NSP, where both increased microbial fermentation (Choct et al. 1996) and increased microbial numbers in the small intestine (Smits et al. 1998) appear to be either the result of, or a contributing factor to, the deleterious effects caused by elevated intestinal viscosity. Langhout et al. (2000) demonstrated that microbial fermentation, intestinal viscosity and associated antinutritional effects were higher in conventionally raised as opposed to germ-free chickens when fed a synthetic viscous compound.

The present authors are not aware of any quantitative studies examining the effect of viscosity on the intestinal microflora of pigs. However, it has been noted that increased viscosity slows transit time of digesta through the upper small intestine of pigs (Cherbut et al. 1990), which would provide more time for microbial pathogens to proliferate. Increased intestinal proliferation of pathogenic Escherichia coli has been seen with addition of either guar gum (McDonald et al. 1999) or pearl barley (McDonald et al. 2000) to the diet of weaner pigs experimentally infected with enterotoxigenic haemolytic $E$. coli. These two types of soluble NSP were both highly fermentable and viscous in nature, which raises the question of whether fermentability, viscosity or a combination of both is likely to influence the porcine small intestinal microflora. Postweaning colibacillosis (PWC) is the most common intestinal disorder of pigs in the immediate post-weaning period, and is associated with proliferation of enterotoxigenic haemolytic E. coli in the small intestine (Gyles, 1993).
The aim of the present study was to record the effects of increased intestinal viscosity on the intestinal tract in weaner pigs in isolation from the influence of increased fermentation. This was achieved by feeding weaner pigs a low-fibre rice-based experimental diet supplemented with carboxymethylcellulose (CMC), a water-soluble synthetic viscous polysaccharide resistant to microbial fermentation. Piglet growth and faecal excretion of haemolytic E. coli were monitored over a $13 \mathrm{~d}$ period before the pigs were slaughtered and carcass and gastrointestinal variables measured.

\section{Materials and methods}

Diets

Three experimental diets based on cooked white rice were used (presented in Table 1). The rice-without-CMC diet comprised mainly cooked medium-grain white rice (Sunwhite Calrose ${ }^{\circledR}$; Ricegrowers Cooperative, Leeton, NSW, Australia), balanced for weaner nutritional requirements with an animal protein supplement. The other two diets contained cooked white rice plus an animal protein supplement with the addition of either a low-viscosity CMC (rice + low-viscosity CMC; 50$200 \mathrm{mPa} \cdot \mathrm{s}$ for a solution of $40 \mathrm{~g} / \mathrm{l}$ at $25^{\circ} \mathrm{C}$, Sigma Aldrich C-5678; Sigma Chemical Co., St. Louis, MO, USA) or a medium viscosity CMC (referred to as rice + high-viscosity $\mathrm{CMC}$ in this trial; $400-800 \mathrm{mPa} \cdot \mathrm{s}$ for a solution of $20 \mathrm{~g} / 1$ at $25^{\circ} \mathrm{C}$, Sigma Aldrich C-4888; Sigma Chemical Co.) respectively. The inclusion of CMC was $40 \mathrm{~g} / \mathrm{kg}$ air-dry diet. Minor adjustments were made in amounts of ingredients in diets rice + lowviscosity $\mathrm{CMC}$ and rice + high-viscosity $\mathrm{CMC}$ to ensure

Table 1. Composition and analysis of experimental diets ( $\mathrm{g} / \mathrm{kg}$ air-dry diet)

\begin{tabular}{|c|c|c|c|}
\hline \multirow[b]{2}{*}{ Ingredient } & \multicolumn{3}{|c|}{ Dietary group } \\
\hline & Rice & $\begin{array}{c}\text { Rice + low-viscosity } \\
\text { CMC }\end{array}$ & $\begin{array}{c}\text { Rice }+ \text { high-viscosity } \\
\text { CMC }\end{array}$ \\
\hline White rice & $699 \cdot 4$ & $661 \cdot 8$ & $661 \cdot 8$ \\
\hline L-Threonine & 0.6 & 0.6 & 0.6 \\
\hline Choline chloride & 0.4 & 0.4 & 0.4 \\
\hline Vitamin+mineral premix* & 1.5 & 1.5 & 1.5 \\
\hline Blood meal & $25 \cdot 3$ & $25 \cdot 1$ & $25 \cdot 1$ \\
\hline Meat and bone meal & 3.6 & 3.6 & 3.6 \\
\hline Fish meal & $151 \cdot 7$ & $150 \cdot 5$ & $150 \cdot 5$ \\
\hline Skimmed-milk powder & $79 \cdot 4$ & 78.7 & 78.7 \\
\hline Dicalcium phosphate & 17.9 & $17 \cdot 8$ & $17 \cdot 8$ \\
\hline Low-viscosity CMC & - & $40 \cdot 0$ & - \\
\hline Medium-viscosity CMC & - & - & $40 \cdot 0$ \\
\hline Celite $545^{\circledR} \dagger$ & $20 \cdot 0$ & $20 \cdot 0$ & $20 \cdot 0$ \\
\hline \multicolumn{4}{|l|}{ Calculated analysis } \\
\hline $\mathrm{DE}(\mathrm{MJ} / \mathrm{kg})$ & 14.9 & 14.4 & $14 \cdot 4$ \\
\hline Lysine & 12 & 12 & 12 \\
\hline \multicolumn{4}{|l|}{ Chemical analysis (\%) } \\
\hline Crude protein & $19 \cdot 8$ & $19 \cdot 2$ & $19 \cdot 2$ \\
\hline Crude fibre & 0.4 & 0.4 & 0.4 \\
\hline
\end{tabular}

CMC, carboxymethylcellulose; DE, digestible energy.

${ }^{*}$ Provided the following nutrients ( $\mathrm{mg} / \mathrm{kg}$ air-dry diet): retinyl acetate 3.44 , cholecalciferol $0.065, \alpha$-tocophenyl acetate 20 , menadione 4.4 , riboflavin 4 , pyridoxine $1 \cdot 6$, cyanocobalamin 0.02 , pantothenic acid 14, nicotinic acid 20, Co 0.2, I 0.6, Fe 120, Mn 60, Zn 100, Cu 10, Se 0.13.

†Celite 545 (Aldrich Chemical Company, Milwaukee, USA, cat. no. 41,993-1). 
energy and protein content were as close as possible to the rice diet without $\mathrm{CMC}$.

\section{Animals}

Thirty-two female pigs were weaned at $19-21 \mathrm{~d}$ of age. Eight pigs were killed on the day of weaning for measurement of intestinal organ and carcass weight. Twenty-four pigs were transported to the Medina Research Station, Perth, Western Australia, where they were allocated to one of the three dietary groups such that the average weight was similar per group. Pigs were housed in pairs within elevated pens, and fed ad libitum for $13 \mathrm{~d}$ after weaning. Daily individual body weights and pen voluntary food intake records were kept, and faecal swabs were cultured for presence of haemolytic E. coli on days 8 to 12 post-weaning. One pig from the rice + high-viscosity CMC group was excluded as it failed to eat and lost body condition. At the end of the $13 \mathrm{~d}$ period, the pigs were killed $1.5 \mathrm{~h}$ after feeding. Pigs were fed at staggered intervals for $5 \mathrm{~d}$ beforehand so they would be accustomed to their feeding time. Ethical approval was obtained for this study from the Animal Experimentation Ethics Committee (98MD18).

\section{Collection of intestinal samples}

Pigs were fed their morning meal on the day of sampling. Live weight was recorded for each pig immediately before administering a single intramuscular injection of ketamine (20 mg/kg, $100 \mathrm{mg} / \mathrm{ml}$; Ketamil, Ilium; Troy Laboratories Pty. Ltd., Smithfield, NSW, Australia) combined with xylazine $(2.2 \mathrm{mg} / \mathrm{kg}, 20 \mathrm{mg} / \mathrm{ml}$; Xylazil-20, Ilium) to induce general anaesthesia. Once the pig was satisfactorily anaesthetised, a lethal dose of sodium barbiturate solution was injected into the heart. Cervical dislocation and exsanguination followed, reducing the amount of blood present as a potential contaminant during the collection of samples. Faecal samples were collected and the gastrointestinal tract was removed and divided into four segments (stomach, small intestine, caecum and colon), which were tied off with string before separation. The full weight of each segment was weighed. The small intestine was stripped free of its mesentery, laid out on a table and divided into three sections of equal length using the same procedure.

Keyhole incisions were made and separate sterile swabs placed in the digesta and wiped along the mucosal surface of the duodenum, ileum, caecum and rectum before rolling onto blood agar plates $(50 \mathrm{~g}$ defibrinated sheep blood/1, trypticase soyabean agar, $40 \mathrm{~g} / 1$; Becton Dickinson and Co., Cockeysville, MD, USA). All plates were kept at room temperature until they were streaked out for single colonies and placed in a hot room at $37^{\circ} \mathrm{C}$ to incubate overnight in air. Digesta samples were collected into jars from the first and third sections of the small intestine, and a section of the small intestinal wall was collected from the mid-point of the middle section and placed into formalin $(100 \mathrm{ml} / \mathrm{l})$ for subsequent processing and histological measurement.

The colon was also divided into the proximal and distal colon. Proximal colonic digesta were collected from the section of colon closest to the caecum, while distal colonic digesta were taken from the apex of the spiral colon. The $\mathrm{pH}$ of digesta was measured immediately after removal of digesta from the intestine by inserting the electrode of a portable $\mathrm{pH}$ meter (Schindengen $\mathrm{pH}$ Boy-2; Schindengen Electric MFG, Tokyo, Japan) into the collected sample. Samples were kept on ice until transferred to a freezer at $-20^{\circ} \mathrm{C}$ within $2 \mathrm{~h}$. Each intestinal segment was then washed and blotted dry and an empty segment weight measured.

Histological sections were prepared and intestinal morphology recorded using an image analyser (Optimas; a.e.s., Victoria Park, Western Australia, Australia), as previously described (McDonald et al. 1999). In addition to measurements of small intestinal villus height and crypt depth, the total cross-sectional width of the underlying muscle layers was recorded, and the villus height:crypt depth ratio was calculated.

\section{Microbiological assessment}

Following overnight incubation, blood agar plates were assessed for the presence of $\beta$-haemolytic colonies with a morphology characteristic of $E$. coli. To allow a quantitative comparison between groups, a visual estimation was made of the proportion of viable bacterial colonies that were $\beta$ haemolytic colonies characteristic of $E$. coli. This estimation was expressed as \% total bacterial population on the plate. Biochemical and serological tests were conducted on representative colony-forming units from each pig to confirm identification. Isolates of $E$. coli from each pig positive for $E$. coli were transferred to sterile nutrient agar slopes and sent to the National E. coli Laboratory at the Department of Natural Resources and Environment Agriculture, Bendigo, Victoria, Australia, for serotyping by slide co-agglutination (Hampson et al. 1993).

\section{Analyses}

The \% DM of the digesta and faecal samples was determined by weighing each sample, oven-drying for $48 \mathrm{~h}$ at $105^{\circ} \mathrm{C}$, then reweighing. To determine volatile fatty acid (VFA) concentration $\left(\mathrm{C}_{2}: \mathrm{C}_{6}\right)$, thawed digesta samples from the ileum, caecum, proximal colon and distal colon were diluted either 1:1 (w/v) (ileal digesta) or $1: 2(\mathrm{w} / \mathrm{v})$ (caecal and colonic digesta) with $3.3 \mathrm{M}$-phosphoric acid, mixed, centrifuged and the supernatant fraction analysed chromatographically. The supernatant fraction $(0 \cdot 1 \mathrm{ml})$ was added to $1 \mathrm{ml}$ internal standard solution containing valeric acid before processing on a capillary GC. A working standard and a control (distilled water) were included in each assay run, where the working standard contained acetic acid $(60 \mathrm{~mm})$, propionic acid $(20 \mathrm{~mm})$, isobutyric acid $(6.67 \mathrm{~mm})$, butyric acid $(20 \mathrm{~mm})$, isovaleric acid $(10 \mathrm{~mm})$, valeric acid (10 mM), and caproic acid (4 mM). The Hewlett Packard 5890A capillary GC (Agilent Technologies, Forrest Hill, Victoria, Australia) was maintained at injector and detector FID settings of $260^{\circ} \mathrm{C}$ and $265^{\circ} \mathrm{C}$ respectively, an initial and final oven temperature of $120^{\circ} \mathrm{C}$ and $240^{\circ} \mathrm{C}$, a carrier gas flow rate of $5 \mathrm{ml} / \mathrm{min}$ and a split-flow rate of $70 \mathrm{ml} / \mathrm{min}$. The Hewlett Packard Chemstation integration system was used to calculate the VFA concentration from the area of the peaks. 


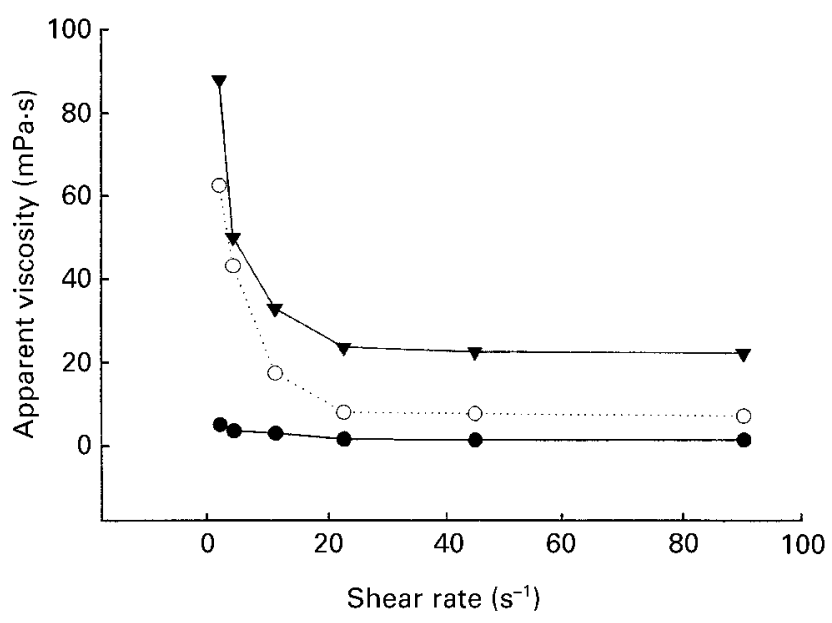

Fig. 1. Effect of shear rate on apparent viscosity of cooked ricebased diets at $25^{\circ} \mathrm{C}$ containing no carboxymethylcellulose $(\bullet)(n 8)$, low-viscosity carboxymethylcellulose $(O)(n 8)$, or high-viscosity carboxymethylcellulose $(\boldsymbol{\nabla})(n 7)$, where carboxymethylcellulose is included at $40 \mathrm{~g} / \mathrm{kg}$ diet. For details of diets and procedures, see Table 1 and pp. 488-490.

\section{Viscosity}

Digesta samples taken from the large intestine and from pigs fed the rice diet were very dry and it was difficult to obtain more than $0 \cdot 1 \mathrm{ml}$ supernatant fraction from the samples by simply centrifuging the digesta sample. Accordingly, in this study, all intestinal samples were diluted 1:1 with distilled water to enable comparison between dietary groups and between sites along the intestine. This also made measurement of small intestinal viscosities easier as digesta was a very thick paste in pigs fed the diet with the highest viscosity CMC. Within $30 \mathrm{~min}$ of collection, digesta samples were diluted 1:1 with distilled water, mixed on a vortex, and centrifuged at $12000 \mathrm{~g}$ for $8 \mathrm{~min}$ (Sigma benchtop centrifuge 1-15; Quantum Scientific Pty Ltd, Milton, Queensland, Australia). The supernatant fraction $(0.5 \mathrm{ml})$ was placed in a Brookfield LVDV-II + cone-plate rotational viscometer (CP40; Brookfield Engineering Laboratories Inc., Stoughton, MA, USA) and the viscosity of all samples was measured at a shear rate of $60 \mathrm{~s}^{-1}$. The viscosity value was recorded as an apparent viscosity.

The diets and digesta containing CMC behaved as a nonNewtonian fluid and displayed shear-thinning behaviour (see Fig. 1), where the viscosity reading is dependent on the shear rate of measurement. To minimise the effects of shear thinning and thixotropy on the viscometer reading, one reading was taken at $60 \mathrm{~s}^{-1}$ immediately after the reading stabilised, in a maximum time of $60 \mathrm{~s} / \mathrm{sample}$. The shear rate of $60 \mathrm{~s}^{-1}$ allowed the most accurate viscometer reading for the range of viscosities being measured and allowed comparison between sites in the small and large intestine. The flow behaviour of CMC diets and digesta fitted a power law relationship that is typical of a weak gel.

\section{Presentation of data and statistical analyses}

The pool of VFA was calculated by multiplying the concentration of VFA within an intestinal segment by the weight of the contents. In the large intestine, the proximal and distal colonic digesta weights were averaged for this calculation. In the small intestine the digesta weight of the last segment was estimated as one third of that from the whole small intestine, as the small intestine was divided equally into three sections. This weight was an underestimation, as there tended to be more digesta in the last third compared to the other two thirds of the small intestine. The amount of VFA produced on a DM basis was calculated by dividing the concentration of VFA by the \% DM of the same digesta.

Statistical analyses were conducted using Statview for

Table 2. Average voluntary food consumption, whole-body and intestinal growth of pigs fed cooked rice-based diets with or without the addition of $40 \mathrm{~g}$ carboxymethylcellulose (CMC) $/ \mathrm{kg}$ diet for $13 \mathrm{~d}$ following weaning*

(Mean values for eight pigs per rice and rice + low viscosity CMC groups, mean values for seven pigs per rice + high viscosity CMC group)

\begin{tabular}{|c|c|c|c|c|c|}
\hline & \multirow[b]{2}{*}{ Rice } & \multicolumn{3}{|c|}{ Dietary treatment } & \multirow[b]{2}{*}{$\begin{array}{c}\text { Statistical significance } \\
\text { of effect: } P\end{array}$} \\
\hline & & $\begin{array}{c}\text { Rice + low-viscosity } \\
\text { CMC }\end{array}$ & $\begin{array}{c}\text { Rice }+ \text { high-viscosity } \\
\text { CMC }\end{array}$ & SED & \\
\hline \multicolumn{6}{|l|}{ Daily food consumption } \\
\hline DM intake (g/d per pig & 218 & 235 & 221 & 25 & NS \\
\hline DE intake (MJ/d per pig) & 3.25 & $3 \cdot 39$ & $3 \cdot 19$ & 0.37 & NS \\
\hline \multicolumn{6}{|c|}{ Daily growth rates ( $\mathrm{g} / \mathrm{d}$ per pig) } \\
\hline Live-weight gain & $290 \cdot 8^{\mathrm{a}}$ & $393 \cdot 2^{b}$ & $325 \cdot 0^{\mathrm{ab}}$ & 63.4 & 0.046 \\
\hline Carcass gain ${ }^{\dagger}$ & $101 \cdot 5^{a b}$ & $120 \cdot 0^{\mathrm{a}}$ & $54 \cdot 0^{\mathrm{b}}$ & $41 \cdot 0$ & 0.054 \\
\hline \multicolumn{6}{|l|}{ Full organ weights $(\mathrm{g}) \ddagger$} \\
\hline Small intestine & $461^{\mathrm{a}}$ & $579^{\mathrm{b}}$ & $589^{b}$ & 78 & 0.03 \\
\hline Large intestine & $186^{\mathrm{a}}$ & $312^{\mathrm{b}}$ & $294^{\mathrm{b}}$ & 36 & $<0.0001$ \\
\hline \multicolumn{6}{|l|}{ Empty organ weights (g) } \\
\hline Small intestine & 420 & 455 & 447 & 14 & NS \\
\hline Large intestine & 109 & 116 & 127 & 21 & NS \\
\hline
\end{tabular}

$\mathrm{DE}$, digestible energy.

${ }^{a, b}$ Mean values within a row with unlike superscript letters were significantly different $(P<0.05)$.

${ }^{*}$ For details of diets and procedures, see Table 1 and pp. 488-490.

† Live weight minus weight of full gastrointestinal tract.

$\ddagger$ Organ weights measured $13 \mathrm{~d}$ after weaning. 
Table 3. The effect of dietary carboxymethylcellulose (CMC) $(40 \mathrm{~g} / \mathrm{kg})$ added to a cooked rice-based diet on the presence of diarrhoea in pigs after weaning ${ }^{*} \dagger$

\begin{tabular}{|c|c|c|c|c|}
\hline Diet & Day $7 \ddagger$ & Day 8‡ & Day 9¥ & Day $10 \ddagger$ \\
\hline Rice & $0 / 8^{a}$ & $1 / 8^{\mathrm{a}}$ & $0 / 8^{a}$ & $0 / 8^{a}$ \\
\hline Rice+low-viscosity CMC & $5 / 8^{b}$ & $3 / 8^{b}$ & $4 / 8^{b}$ & $4 / 8^{b}$ \\
\hline Rice+high-viscosity CMC & $7 / 7^{\mathrm{b}}$ & $7 / 7^{\mathrm{b}}$ & $7 / 7^{\mathrm{b}}$ & $5 / 7^{\mathrm{b}}$ \\
\hline$P$ value & $<0.05$ & $<0.05$ & $<0.05$ & $<0.05$ \\
\hline
\end{tabular}

${ }^{a, b}$ Mean values within a column with unlike superscript letters were significantly different: $P<0.05$.

* For details of diets and procedures, see Table 1 and pp. 488-490.

$\dagger$ Expressed as number of pigs with diarrhoea as a proportion of total number of pigs in the group.

$\ddagger$ Day number is the number of days after weaning (weaning is day 1 ).

Windows (version 5.0; SAS Institute Corporation, Cary, NC, USA). One-way ANOVA determined significant differences between treatment groups and the mean values were compared using Fisher's least-significant difference test. Fisher's exact test was used to determine the effect of diet on daily counts of diarrhoea (Table 3). Carcass weight was defined as the live-body weight minus the weight of the full intestinal tract, heart, lungs, spleen and kidneys. The average daily carcass weight as a proportion of the weight of the eight pigs slaughtered on the day of weaning $(86.14 \%$ live weight) was used to calculate weaning carcass weights (Noblet \& Etienne, 1987). The unit of replication was the individual pig for all measurements of body weight, internal measurements and microbiological data, and for food intake the unit of replication was each pen.

\section{Results}

\section{Whole-body and intestinal growth and food intake}

There was no difference in the average voluntary DM intake

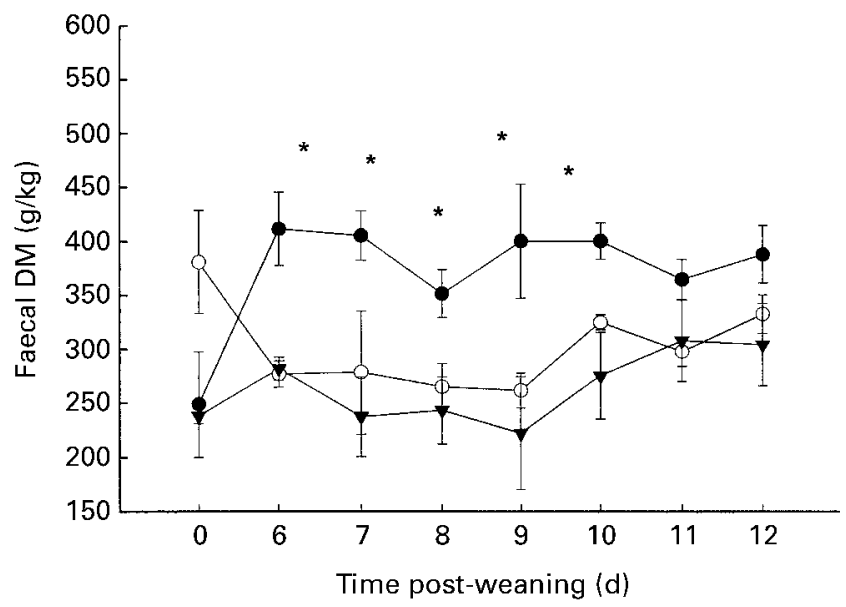

Fig. 2. Daily faecal DM $(\mathrm{g} / \mathrm{kg})$ in pigs fed diets containing no carboxymethylcellulose $(\bullet)(n 8)$, low-viscosity carboxymethylcellulose (O) $(n 8)$, or high-viscosity carboxymethylcellulose $(\mathbf{\nabla})(n 7)$, where carboxymethylcellulose was included at $40 \mathrm{~g} / \mathrm{kg}$ diet. For details of diets and procedures, see Table 1 and pp. 488-490. Values are means with standard deviations represented by vertical bars. Mean values were significantly different from those of the control group: ${ }^{*} P<0.05$. between pigs fed the rice diet, the rice + low-viscosity CMC or the rice + high-viscosity CMC diet (Table 2). Increasing the viscosity of the weaning diet resulted in an increase in live-weight gain $(P<0 \cdot 05)$ (Table 2). Higher intestinal viscosity was also associated with a greater full weight of the intestines $(P<0 \cdot 05)$, which accounted for the greater values for live-weight growth in pigs fed the viscous diets compared with the non-viscous diet. Once the effect of diet on intestinal weights was removed by subtracting the weight of the abdominal viscera, the carcass gain of pigs fed rice + low-viscosity $\mathrm{CMC}$ and rice + high-viscosity CMC was considerably reduced. The addition of the highest viscosity CMC depressed carcass growth relative to pigs fed the rice diet without $\mathrm{CMC}$, but the pigs fed the lower viscosity CMC still had greater carcass gain than those fed the rice diet without CMC. Small intestinal full weights were greatest for pigs fed rice + high-viscosity CMC due to the greater volume of digesta in these pigs.

\section{Faecal consistency}

Pigs fed the viscous diets began to display loose faeces at about 4-5d post-weaning. By the seventh day after weaning, five out of eight of the pigs fed rice + lowviscosity CMC and all of the pigs fed rice + high-viscosity CMC had diarrhoea (Table 3), which corresponded with a decrease in measured faecal \% DM (Fig. 2). Pigs fed rice without CMC remained healthy and only one pig displayed diarrhoea for $1 \mathrm{~d}$ during the trial. When \% DM along the length of the intestinal tract was examined after slaughter, there was a significant reduction in $\% \mathrm{DM}$ of digesta due to addition of CMC (Fig. 3), which was most divergent at the distal end of the tract. The average \% DM in the large intestine on all diets was significantly greater than that of the small intestine.

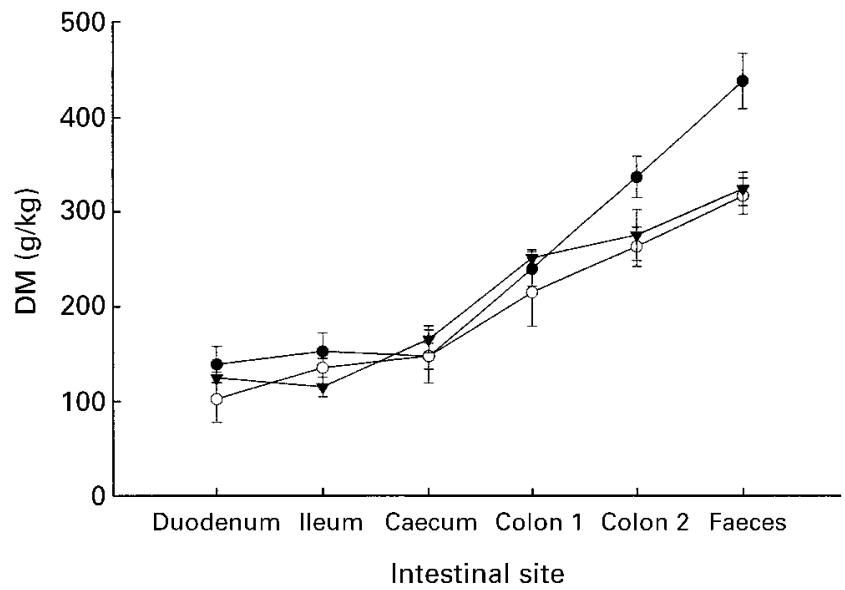

Fig. 3. Digesta DM $(\mathrm{g} / \mathrm{kg})$ along the intestinal tract of $34-\mathrm{d}$-old pigs fed diets containing no carboxymethylcellulose $(\bullet)(n$ 8), low-viscosity carboxymethylcellulose $(0)(n 8)$, or high-viscosity carboxymethylcellulose $(\boldsymbol{\nabla})(n$ 7), where carboxymethylcellulose was included at $40 \mathrm{~g} / \mathrm{kg}$ diet. For details of diets and procedures, see Table 1 and pp. 488-490. Values are means with standard deviations represented by vertical bars. Colon 1 and 2 are the proximal and distal colon sites respectively. The value for $\mathrm{DM}(\mathrm{g} / \mathrm{kg})$ differed significantly among diets $(P=0.0008)$ and intestinal sites $(P<0.0001)$. 


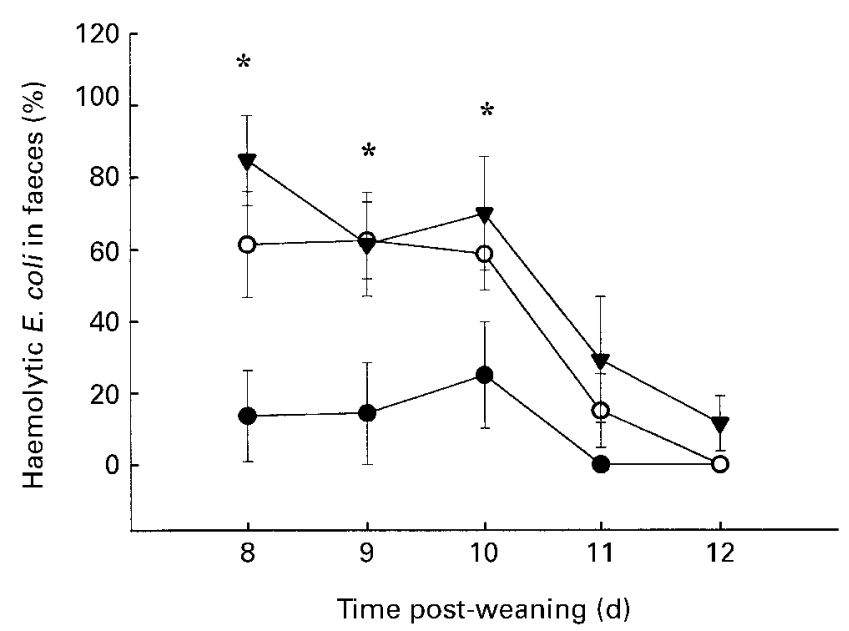

Fig. 4. Daily faecal shedding of haemolytic E. coli in pigs after weaning on three rice-based diets containing no carboxymethylcellulose $(\bullet)(n 8)$, low-viscosity carboxymethylcellulose $(\bigcirc)(n 8)$, or high-viscosity carboxymethylcellulose $(\mathbf{\nabla})(n 8)$, where carboxymethylcellulose was included at $40 \mathrm{~g} / \mathrm{kg}$ diet. Colonisation is expressed as \% bacteria cultured from faeces that were haemolytic E. coli. For details of diets and procedures, see Table 1 and pp. 488-490. Values are means with standard deviations represented by vertical bars. Mean values were significantly different from those of the control group: ${ }^{*} P<0.05$.

\section{Enterotoxigenic E. coli}

Both groups receiving rice $+\mathrm{CMC}$ shed significantly more haemolytic E. coli $(P=0 \cdot 011$, Fig. 4$)$ in their faeces daily than pigs fed rice without $\mathrm{CMC}$, and tended to have a greater intestinal colonisation of haemolytic E. coli at slaughter (Fig. 5). The serotype of E. coli shed from these

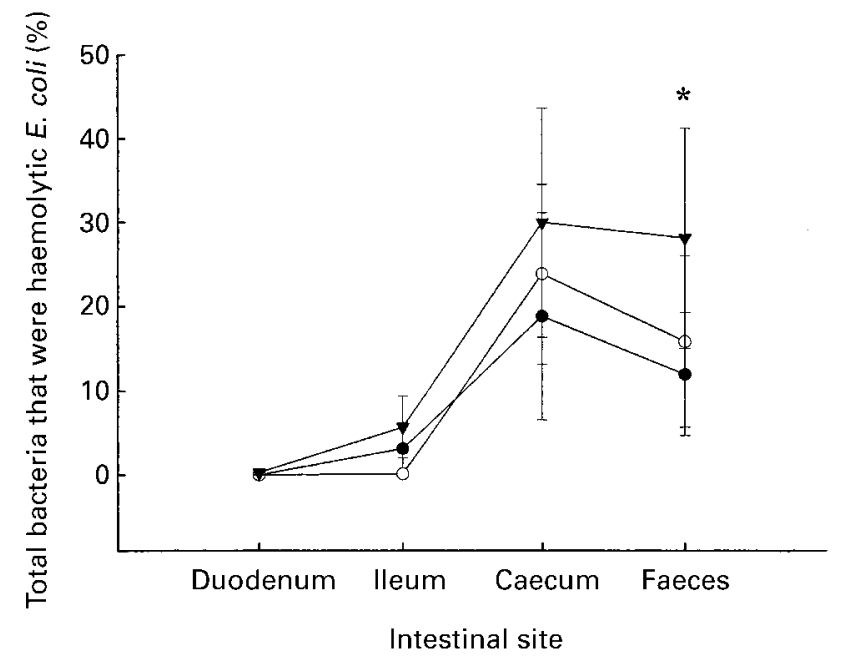

Fig. 5. Colonisation of the intestinal tract of 34-d-old pigs fed diets containing no carboxymethylcellulose $(\bullet)(n$ 8), low-viscosity carboxymethylcellulose $(O)(n 8)$, or high-viscosity carboxymethylcellulose $(\boldsymbol{\nabla})(n 7)$, with haemolytic $E$. coli. Colonisation is expressed as $\%$ bacteria cultured from faeces that were haemolytic $E$. coli. For details of diets and procedures, see Table 1 and pp. 488-490. Values are means with standard deviations represented by vertical bars. Mean values were significantly different from those of the control group: * $P<0.05$. naturally infected pigs in each case was identified as O149;K91;K88.

\section{Intestinal viscosity}

Apparent intestinal viscosity values are recorded in Table 4 . Addition of CMC to the diet significantly increased the apparent viscosity of the digesta supernatant fraction relative to the rice diet in the duodenum $(P<0 \cdot 001)$, ileum $(P<0.001)$ and in the caecum $(P<0.05)$, in a manner reflecting the viscosity of CMC used. Within the two groups of pigs fed the diets containing $\mathrm{CMC}$, the magnitude of apparent viscosity generally decreased from the proximal to distal end of the intestinal tract, although the reduction in viscosity between sites was not statistically significant (results not shown). In the pigs fed the rice diet without $\mathrm{CMC}$, the intestinal apparent viscosity value was relatively constant in the duodenum, ileum and caecum but almost doubled in the proximal colon. This difference was not statistically significant, probably associated with the large variation between pigs. The contents of the proximal colon were very dry and even after dilution it was difficult to collect enough clear supernatant fraction to obtain a steady viscosity measurement in the pigs fed the rice-withoutCMC diet. There was no statistically significant difference in the apparent viscosity of intestinal contents when measured at $4,25,37^{\circ} \mathrm{C}$, after a period of freezing at $-20^{\circ} \mathrm{C}$ or when retested $6 \mathrm{~h}$ after the first measurement.

\section{Morphology of the small intestine}

The height of the small intestinal villi and the width of the muscle layers underlying the intestinal villi were greatest in pigs fed the low-viscosity CMC and smallest in those fed the high-viscosity CMC (Table 4), with the values for the pigs fed the rice diet without $\mathrm{CMC}$ falling between these values. Addition of either low- or high-viscosity CMC to the rice diet was associated with an increase in the crypt depth $(P=0.003)$. The villus height:crypt depth ratio was significantly reduced $(P<0.001)$ in pigs fed the highviscosity $\mathrm{CMC}$ diet as a result of low villus height values. The ratio was identical in the pigs fed rice without $\mathrm{CMC}$ and those fed rice + low-viscosity CMC (1.73).

\section{Intestinal fermentation}

There was no effect of addition of dietary CMC on the concentration of total VFA in the ileum or caecum (Table 5). VFA concentrations were lower in the colon of pigs fed diets including CMC compared with those fed the diet without $\mathrm{CMC}$, confirming that $\mathrm{CMC}$ was not significantly contributing to fermentation within the tract. Values for $\mathrm{pH}$ also differed significantly in the proximal $(P=0.035)$ and distal $(P<0.0001)$ colon, but not more proximally in the tract, with the $\mathrm{pH}$ values being lower in pigs fed the diets containing CMC than in pigs fed rice without CMC (Table 4). The average total pool of VFA in the caecum and colon collectively was significantly increased by the addition of CMC $(P<0.05)$, with the mean values being 5.77 (SE 0.6) $\mathrm{mmol} / \mathrm{pig}$, 9.40 (SE 1.2) $\mathrm{mmol} / \mathrm{pig}$ and 8.11 (SE 0.9) $\mathrm{mmol} / \mathrm{pig}$ for pigs fed the rice diet without $\mathrm{CMC}$, the 
Table 4. Intestinal morphology and mean apparent intestinal viscosity of pigs fed a cooked rice-based diet with or without the inclusion of $40 \mathrm{~g}$ carboxymethylcellulose (CMC)/kg diet for $13 \mathrm{~d}$ following weaning*

(Mean values for eight pigs per rice and rice + low viscosity CMC groups, mean values for seven pigs per rice + high viscosity CMC group)

\begin{tabular}{|c|c|c|c|c|c|}
\hline & \multicolumn{3}{|c|}{ Dietary treatment } & \multirow[b]{2}{*}{ SED } & \multirow[b]{2}{*}{$\begin{array}{c}\text { Statistical significance } \\
\text { of effect: } P\end{array}$} \\
\hline & Rice & $\begin{array}{c}\text { Rice + low-viscosity } \\
\text { CMC }\end{array}$ & $\begin{array}{c}\text { Rice }+ \text { high-viscosity } \\
\text { CMC }\end{array}$ & & \\
\hline \multicolumn{6}{|c|}{ Apparent intestinal viscosity (mPa.s) } \\
\hline Duodenum & $1.42^{\mathrm{a}}$ & $6 \cdot 14^{\mathrm{b}}$ & $8.93^{b}$ & $2 \cdot 63$ & 0.0007 \\
\hline lleum & $1 \cdot 41^{\mathrm{a}}$ & $6 \cdot 04^{\mathrm{b}}$ & $7 \cdot 91^{\mathrm{b}}$ & $2 \cdot 20$ & 0.0006 \\
\hline Caecum & $1 \cdot 67^{\mathrm{a}}$ & $4.09^{a b}$ & $6 \cdot 18^{\mathrm{b}}$ & $2 \cdot 43$ & 0.0277 \\
\hline Poximal colon & $2 \cdot 48$ & $4 \cdot 33$ & $5 \cdot 20$ & $2 \cdot 08$ & NS \\
\hline \multicolumn{6}{|c|}{ Small intestinal villi measurements $(\mu \mathrm{m})$} \\
\hline Villus height & $409^{a^{\prime}}$ & $451^{\mathrm{b}}$ & $363^{\mathrm{c}}$ & 106 & $<0.0001$ \\
\hline Crypt depth & $249^{a}$ & $273^{b}$ & $271^{\mathrm{b}}$ & 41 & 0.0003 \\
\hline Villus height:crypt depth & $1 \cdot 73^{\mathrm{a}}$ & $1.73^{a}$ & $1.39^{b}$ & 0.55 & 0.0002 \\
\hline Muscle thickness & $289^{a}$ & $312^{\mathrm{b}}$ & $238^{\mathrm{c}}$ & 51 & $<0.0001$ \\
\hline
\end{tabular}

a,b Mean values within a row with unlike superscript letters were significantly different. $(P<0.05)$.

${ }^{*}$ For details of diets and procedures, see Table 1 and pp. 488-490.

rice + low-viscosity $\mathrm{CMC}$ or rice + high-viscosity $\mathrm{CMC}$ respectively.

\section{Discussion}

\section{Viscosity}

There are inherent difficulties in measuring the viscosity of the chyme along the intestinal tract that deserve mention before discussing the influence of viscosity on the gut. Viscosity is often measured on the liquid portion of digesta as separated by centrifugation (Blackburn \& Johnson, 1981; Bedford \& Classen, 1992; Gallaher et al. 1993; Choct et al. 1996; Smits et al. 1997), although a few studies have measured the viscosity of the whole digesta (CameronSmith et al. 1994; Larsen et al. 1994; Ellis et al. 1995). In the upper regions of the intestinal tract where there is greater water content, the magnitude of viscosity is most likely to be driven by components in the liquid fraction. In the large intestine there is relatively less fluid and the solid particles play an important role in generating viscosity (Morris, 1992; McRorie et al. 1998, 2000). The supernatant fraction apparent viscosity in this trial therefore has been viewed as an estimate of whole digesta viscosity, to be used for purposes of comparison between diets rather than as an absolute quantification.

Dilution of digesta, such as by intestinal secretions, reduces the apparent viscosity of the sample. Dilution ex

Table 5. Mean volatile fatty acid (VFA) concentrations and $\mathrm{pH}$ values in the intestinal tract of pigs fed cooked rice-based diets with or without the inclusion of $40 \mathrm{~g}$ carboxymethylcellulose $(\mathrm{CMC}) / \mathrm{kg}$ diet for $13 \mathrm{~d}$ following weaning ${ }^{*}$

(Mean values for eight pigs per rice and rice + low viscosity CMC groups, mean values for seven pigs per rice + high viscosity CMC group)

\begin{tabular}{|c|c|c|c|c|c|}
\hline & \multicolumn{3}{|c|}{ Dietary treatment } & \multirow[b]{2}{*}{ SED } & \multirow[b]{2}{*}{$\begin{array}{c}\text { Statistical significance } \\
\text { of effect: } P\end{array}$} \\
\hline & Rice & $\begin{array}{c}\text { Rice + low-viscosity } \\
\text { CMC }\end{array}$ & $\begin{array}{c}\text { Rice }+ \text { high-viscosity } \\
\text { CMC }\end{array}$ & & \\
\hline \multicolumn{6}{|c|}{ Total VFA (mmol/kg wet digesta) } \\
\hline Ileum & $20 \cdot 2$ & $18 \cdot 5$ & $17 \cdot 4$ & $8 \cdot 7$ & NS \\
\hline Caecum & 94.7 & $89 \cdot 6$ & $89 \cdot 0$ & $15 \cdot 2$ & NS \\
\hline Proximal colon & $93 \cdot 0^{\mathrm{a}}$ & $52 \cdot 2^{b}$ & $50 \cdot 8^{b}$ & $18 \cdot 7$ & 0.002 \\
\hline Distal colon & $65 \cdot 9^{\mathrm{a}}$ & $41 \cdot 6^{b}$ & $31 \cdot 4^{\mathrm{b}}$ & 11.6 & 0.0004 \\
\hline \multicolumn{6}{|c|}{ Total VFA (mmol/kg digesta DM) } \\
\hline Ileum & 211.9 & $140 \cdot 8$ & $161 \cdot 0$ & 88.2 & NS \\
\hline Caecum & 734.9 & $550 \cdot 9$ & 571.4 & $252 \cdot 0$ & NS \\
\hline Proximal colon & $402 \cdot 7$ & 220.5 & $186 \cdot 2$ & 105.0 & NS \\
\hline Distal colon & $204 \cdot 9$ & $162 \cdot 7$ & $129 \cdot 9$ & $61 \cdot 1$ & NS \\
\hline \multicolumn{6}{|l|}{$\mathrm{pH}$ values } \\
\hline Duodenum & $6 \cdot 19$ & $5 \cdot 80$ & $5 \cdot 74$ & 0.36 & NS \\
\hline Ileum & $6 \cdot 67$ & $6 \cdot 86$ & $6 \cdot 71$ & 0.39 & NS \\
\hline Caecum & $6 \cdot 33$ & $6 \cdot 27$ & $6 \cdot 26$ & 0.14 & NS \\
\hline Proximal colon & $6 \cdot 57^{\mathrm{a}}$ & $6 \cdot 25^{\mathrm{b}}$ & $6 \cdot 34^{\mathrm{ab}}$ & 0.19 & 0.035 \\
\hline Distal colon & $7 \cdot 08^{a}$ & $6 \cdot 15^{\mathrm{b}}$ & $6 \cdot 22^{\mathrm{b}}$ & 0.14 & $<0.0001$ \\
\hline Faeces & $7 \cdot 06^{a}$ & $6 \cdot 19^{b}$ & $6 \cdot 22^{b}$ & $0 \cdot 18$ & $<0.0001$ \\
\hline
\end{tabular}

a,b Mean values within a row with unlike superscript letters were significantly different $(P<0 \cdot 05)$.

${ }^{\star}$ For details of diets and procedures, see Table 1 and pp. 488-490. 
vivo underestimated the apparent viscosity of the samples containing CMC compared with those without $\mathrm{CMC}$ due to the weak gel behaviour of $\mathrm{CMC}$, although the apparent viscosities of the diluted solutions containing $\mathrm{CMC}$ remained higher than those without $\mathrm{CMC}$ at all shear rates (Fig. 1, Table 4). As the small intestine has been the main site sampled for viscosity measurements, the need for dilution does not seem to have been a commonly recorded problem, although some authors have diluted gastric and small intestinal samples (Cameron-Smith et al. 1994) or caecal samples (Topping et al. 1988) with water in a 1:1 (w/v) ratio or up to a designated volume (Ikegami et al. 1990) to enable measurement of viscosity. For the purposes of the present study, the measurement of viscosity was required to establish that $\mathrm{CMC}$ was creating a significantly different viscosity within the intestinal lumen. To this end, the apparent viscosity (that recorded directly by a viscometer) indicated this was successful.

The dietary composition, the extent of hydration of the dietary NSP and the time of measurement of viscosity after feeding all influence the value obtained for measurement of intestinal viscosity. All pigs in this study were killed $1.5 \mathrm{~h}$ after feeding to minimise timing complications and to target the maximal viscosity, based on the fact that viscosity of gastric digesta was highest 30-60 min post-feeding for CMC (Rainbird \& Low, 1986a) and guar gum (Ellis et al. 1995) in grower pigs. The composition of the non-NSP components of the diet such as starch may also potentially enhance or decrease the viscosity (Rainbird, 1986).

\section{Whole-body and intestinal development}

Inclusion of the synthetic non-fermentable compound CMC to the diet of weaner pigs induced significant changes in intestinal structure within $13 \mathrm{~d}$ after weaning. The full small and large intestines increased in weight in response to the addition of CMC to the diet. The major proportion of the increase in weight was due to the increased weight of the digesta, indicated by the fact that the empty organ weights were not significantly different between dietary groups. Larsen et al. (1994) also found the empty intestinal weights of rats fed $\mathrm{CMC}$ tended to be non-significantly heavier with increasing viscosity of CMC in the diet. The increase in empty and full intestinal weights tends to be more significant when the dietary NSP are both viscous and fermentable, such as guar gum or pectin (Ikegami et al. 1990; Pluske et al. 1996; McDonald et al. 1999). However, it is now clear that viscosity alone can induce major increases in empty organ weights when the diet is fed for a longer period than in this study (Elsenhans \& Caspary, 2000). It is possible that the empty intestinal weights in the weaner pigs may have increased had the animals been given a longer adaptation period.

Although the average daily voluntary food intakes were similar, pigs fed the diets with CMC had significantly greater digesta weights than those pigs fed the unsupplemented rice diet. Gel-forming substances such as CMC have the ability to hold water and swell, which would increase the weight of digesta that contained CMC. An increase in both the intestinal water content and water intake has been noted upon feeding of viscous polysaccharides in poultry (van der
Klis et al. 1993; Choct et al. 1996; Smits et al. 1998). The presence of viscous polysaccharides in the lumen of the small intestine can also increase endogenous secretions such as pancreatic enzymes and mucus (Ikegami et al. 1990), and reduce water absorption (van der Klis et al. 1993), all of which would increase the water content of the digesta. In addition, a decrease in the rate of passage of digesta through the jejunum and ileum has been noted in poultry fed CMC (van der Klis et al. 1993) and rats fed guar gum (Brown et al. 1988), and may have caused pooling of digesta in the small intestine. This would have further increased the digesta weight measured at a point in time.

The difference between carcass and whole-body growth rates of pigs fed the viscous diets compared with the rice diet highlights the importance of recognising that a significant proportion of the total growth in pigs fed a fibrous diet (when compared to low- or non-fibrous diets) may be due to growth of the gut. This is especially relevant for weaner pigs as they preferentially develop their gastrointestinal tract to cope with the new weaning diet before muscle accretion begins in earnest (Cranwell \& Moughan, 1989). There also appears to have been an effect of degree of viscosity on growth of the carcass, where the low-viscosity CMC was associated with slightly improved gain, and the higher viscosity CMC was associated with reduced carcass gain.

It is surprising that the pigs fed rice + low-viscosity CMC gained weight relative to pigs fed rice without $\mathrm{CMC}$, as viscous compounds have been shown to hinder nutrient and energy absorption in the small intestine of pigs (Rainbird et al. 1984; Ehrlein \& Stockmann, 1998a). Addition of the low-viscosity CMC to the rice diet increased the small intestinal villus height and crypt depth without altering the shape of the finger-like villi. This is considered beneficial, as longer villi contain a greater number of mature cells capable of absorbing nutrients, and villus height correlates positively with empty body-weight gain and DM intake (Pluske, 1993). Together with a slightly higher food intake, this may explain the greater growth in pigs fed low-viscosity CMC.

The villus height and villus height:crypt depth ratio of pigs fed rice + high viscosity CMC, however, was significantly reduced, suggesting a reduced overall capacity for digestion and absorption of nutrients compared to the pigs on the other two diets. Reduction of villous height has recently been demonstrated in chickens fed viscous highly methylated citrus pectin (Langhout et al. 2000), a diet that is also associated with depression of growth rate (Langhout, 1998). It is possible that a small increase in intestinal viscosity may be beneficial up to a threshold, beyond which value the viscosity becomes detrimental to the assimilation of nutrients through the gut, and therefore to the growth of the animal.

The thickness of the muscle layer underlying the small intestinal epithelium followed a similar dietary trend as the villous height, being greater upon addition of low-viscosity $\mathrm{CMC}$ to the rice diet and reduced when the high-viscosity CMC was included. An increase in muscle thickness would logically be expected with greater bulk and weight of digesta, as a means of coping with the requirements of peristalsis. It was therefore expected that the highest 
viscosity CMC would induce the greatest increase in muscle thickness, but this was not the case.

\section{Intestinal fermentation}

The choice of CMC for the present study was based on the premise that the compound would not be fermented to any significant extent, allowing an examination of the effects of viscosity independent of potential effects of fermentation. The lack of significant fermentation of CMC was confirmed in pigs fed CMC by measurements of VFA, which give an indication of the rate of VFA production, and which were either not higher (in the ileum and caecum) or were significantly lower (in the colon) than in pigs fed the diet not containing $\mathrm{CMC}$, on a wet basis ( $\mathrm{mmol} / \mathrm{kg}$ wet digesta).

The $\mathrm{pH}$ values in the large intestine were unexpectedly lower in pigs fed rice + CMC diets compared with the plain rice diet, which normally indicates an increase in microbial fermentation and coincides with increased end product formation of VFA (Pluske et al. 1996). A lower ileal $\mathrm{pH}$ in animals fed CMC has been noted in chickens fed CMC (van der Klis et al. 1993; Smits et al. 1998) and could be related to a change in the relative populations of microbes. Alternatively, the increased unstirred water layer induced by the presence of $\mathrm{CMC}$ in the intestinal tract may interfere with the exchange of $\mathrm{HCO}_{3}{ }^{-}$and $\mathrm{H}^{+}$ions across the epithelium, affecting the intralumen $\mathrm{pH}$ (van der Klis et al. 1993).

Although the rate of production of $\mathrm{VFA} / \mathrm{kg}$ wet digesta was greatest in pigs fed rice without CMC, the total pool of VFA in the caecum and colon was significantly higher in those pigs fed rice $+\mathrm{CMC}$ due to the large volume of digesta. Low concentrations of VFA occurring simultaneously with large pools of VFA have also been noticed when feeding CMC to rats (Wyatt et al. 1988), and were attributed to the large amount of digesta in the organ examined. A greater accumulation of VFA in the caecum and colon at any one time would have induced a more acidic $\mathrm{pH}$ value, adding another possible explanation for the lower $\mathrm{pH}$ values found.

The fact that $\mathrm{CMC}$ was still able to exert a water-holding capacity in the distal colon infers that there was no significant breakdown of CMC by fermentation (Tomlin et al. 1986), and this is supported by work in rats where little CMC was broken down at the distal colon (Wyatt et al. 1988).

\section{Changes in intestinal microflora and diarrhoea}

The microbe of interest in the current study was a strain of haemolytic E. coli. The present study did not involve any experimental infection with $E$. coli and was originally intended as a preliminary trial for such an experimental infection trial. Unexpectedly, the pigs in this study succumbed to a natural infection of PWC caused by the intestinal proliferation of enterotoxigenic E. coli serotype O149;K91;K88. The influence of dietary CMC on the faecal shedding of this strain of E. coli and on faecal \% DM was significant. PWC is a difficult disease to reproduce experimentally, requiring pigs to be susceptible to the disease (e.g. possessing intestinal receptors for enterotoxigenic $E$. coli) and requiring a certain level of stress (e.g. cold stress, crowding, fighting) on top of the stress of weaning before disease will occur experimentally. The pigs in this study were kept in a very clean environment at optimal ambient temperature and minimal stress levels. All pigs were housed in one large room with pigs fed rice without CMC less than $0.5 \mathrm{~m}$ away from those fed rice $+\mathrm{CMC}$, enabling easy transmission of infection from one group to another. Nevertheless, only the pigs fed rice + CMC developed PWC.

It is common for haemolytic $E$. coli to appear in increased numbers in the faeces of pigs in the first week after weaning (Hinton et al. 1985; Jensen, 1998). This happens in both healthy and diarrhoeic pigs, although the numbers excreted increase dramatically in those with diarrhoea (Gyles, 1993). There was a clear, statistically significant increase $(P<0.05)$ in the proportion of haemolytic $E$. coli shed in the groups fed rice $+\mathrm{CMC}$ in the present study, and this coincided with the appearance of sloppy faeces that were significantly wetter than those from pigs fed rice without CMC. The pigs fed rice + high-viscosity $\mathrm{CMC}$ had the worst diarrhoea and the highest levels of haemolytic $E$. coli shed in their faeces. The small intestinal villi of these pigs also were atrophied, a common feature seen in PWC (Kenworthy et al. 1967). It is unknown whether the shorter villi in this group were a result of, or a precipitating factor for, the development of intestinal disease.

The addition of viscous polysaccharides that are also fermentable, such as guar gum, to the weaner diet can exacerbate PWC (Mcdonald et al. 1999). Other studies testing non-viscous and fermentable dietary fibres have shown that they have an ability to alleviate PWC (Palmer \& Hulland, 1965; Bertschinger \& Eggenberger, 1978; Thomlinson \& Lawrence, 1981), lending weight to the contention that intestinal viscosity has an influence on this disease. Some studies have tested diets containing fibres that are commonly viscous and fermentable (e.g. oats), but extrapolation of results is difficult because the intestinal viscosity of these diets and intestinal samples was not measured (Okai et al. 1976; Ball \& Aherne, 1982; Etheridge et al. 1984).

Altered microbial activity has been noted in other species in association with increasing small intestinal viscosity (Choct et al. 1996: Smits et al. 1998; Langhout, 1998; Langhout et al. 2000). For example, the numbers of E. coli and total anaerobic counts in the ileum of chickens increased significantly with the addition of citrus pectin (Langhout, 1998), whilst total microbial counts (aerobic and anaerobic) increased in the duodena and jejuna of chickens fed diets containing CMC (Smits et al. 1998). When CMC was included in diets offered to rats there was no increase in the density of bacteria in the caecal or colonic contents, but the bacterial populations changed significantly, with the aerobic bacteria, in particular E. coli, being more numerous in the large intestine (Wyatt et al. 1988).

Smits et al. (1997, 1998) proposed that reduced absorption of nutrients allowed the secondary increase in microbial numbers in the ileum. Viscous polysaccharides are thought to drag digesta to the distal part of the intestines before digestion is complete, providing the substrate for microbial proliferation. Germ-free chicks have both higher $\mathrm{pH}$ and lower viscosity in their intestines than conventionally 
reared chicks (Langhout et al. 2000), suggesting that the presence of microbes and an increase in viscosity are interrelated.

The presence of CMC in the digesta appears to provide an environment that favours establishment and growth of bacteria, especially $E$. coli, as well as providing osmotic drag that accelerates development of clinical diarrhoea (van der Klis et al. 1993). Bacteria possess an array of mechanisms for establishing colonisation within the gut. E. coli possess fimbriae that attach to the brush border of the small intestinal villi, but also allow the bacteria to attach to the mucus lining the intestinal tract (Conway, 1994). CMC adheres to and thickens porcine mucin (Rossi et al. 1996), and may also alter its composition, which in this case may have enhanced the ability of haemolytic E. coli to bind to the mucus lining the intestinal villi.

The presence of CMC in digesta of chicks reduces net $\mathrm{Na}^{+}$and water absorption and increases osmolality (Van der Klis et al. 1993). This would increase digesta water content, and may explain how feeding $\mathrm{CMC}$ at levels of about $10 \%$ to rats results in sloppy faeces, diarrhoea and a faster total transit time (Gohl \& Gohl, 1977; Johnson \& Gee, 1986; Wyatt et al. 1988). Conversely, addition of CMC to oral rehydration solutions offered to healthy rats and those with chronic osmotic diarrhoea or malnutrition has also been positively correlated with increased intestinal water and $\mathrm{Na}^{+}$ absorption (Go et al. 1994). Subsequent work revealed a complex interaction between concentration, chemical composition of CMC and effect on water and $\mathrm{Na}^{+}$ absorption, where only low concentrations of particular types of CMC are capable of enhancing intestinal absorption (Wapnir et al. 1997).

The interplay between viscosity, fermentation and microflora is extremely complex and is undoubtedly altered by the type of fermentative or viscous compounds involved, amongst many other factors. In the present study the addition of CMC to the weaning diet significantly increased intestinal viscosity, altered the structure of the intestine and provided a microenvironment that favoured the proliferation of pathogenic E. coli. These findings have implications for the use of feed ingredients in weaner diets that may significantly increase the intestinal viscosity, such as those containing high levels of soluble NSP. Finally, the inclusion of CMC in weaner diets represents a novel method of inducing experimental PWC without requiring experimental inoculation of E. coli.

\section{Acknowledgements}

This study was supported by a grant from the Australian Pig Research and Development Corporation (PRDC). D.E.M. was in receipt of a postgraduate scholarship from the PRDC. Thanks are due to Ian Robertson for help with statistical analyses and Agriculture WA for the use of the piggery facilities and help with VFA analysis.

\section{References}

Antonious T \& Marquardt RR (1982) Utilisation of rye diets by chicks as affected by lipid type and level and penicillin supplementation. Poultry Science 61, 107-116.
Ball RO \& Aherne FX (1982) Effect of diet complexity and feed restriction on the incidence and severity of diarrhoea in early weaned pigs. Canadian Journal of Animal Science 62, 907-913.

Bedford MR \& Classen HL (1992) Reduction of intestinal viscosity through manipulation of dietary rye and pentosanase concentration is effected through changes in the carbohydrate composition of the intestinal aqueous phase and results in improved growth rate and food conversion efficiency of broiler chicks. Journal of Nutrition 122, 560-569.

Bertschinger HU \& Eggenberger E (1978) Evaluation of low nutrient, high fibre diets for the prevention of porcine Escherichia coli enterotoxaemia. Veterinary Microbiology 3, $281-290$.

Blackburn NA \& Johnson IT (1981) The effect of guar gum on the viscosity of the gastrointestinal contents and on glucose uptake from the perfused jejunum in the rat. British Journal of Nutrition 46, 239-246.

Brown NJ, Worlding J, Rumsey RDE \& Read NW (1988) The effect of guar gum on the distribution of a radiolabelled meal in the gastrointestinal tract of the rat. British Journal of Nutrition 59, 223-231.

Burnett GS (1966) Studies of viscosity as the probable factor involved in the improvement of certain barleys for chickens by enzyme supplementation. British Poultry Science 7, 55-75.

Cameron-Smith D, Collier GR \& O'Dea K (1994) Effect of soluble dietary fibre on the viscosity of gastrointestinal contents and the acute glycaemic response in the rat. British Journal of Nutrition 71, 563-571.

Campbell GL, Rossnagel BG, Classen HL \& Thacker PA (1989) Genotypic and environmental differences in extract viscosity of barley and their relationship to its nutritive value for broiler chickens. Animal Feed Science and Technology 26, 221-230.

Cherbut C, Albina E, Champ M, Coublier JL \& Lecannu G (1990) Action of guar gums on the viscosity of digestive contents and on the gastrointestinal motor function in pigs. Digestion 46, 205-213.

Choct M \& Annison G (1992) Anti-nutritive effect of wheat pentosans in broiler chickens: roles of viscosity and gut microflora. British Poultry Science 33, 821-834.

Choct M, Hughes RJ, Wang J, Bedford MR, Morgan AJ \& Annison G (1996) Increased small intestinal fermentation is partly responsible for the anti-nutritive activity of non-starch polysaccharides in chickens. British Poultry Science 37, 609-621.

Conway PL (1994) Function and regulation of the gastrointestinal microbiota of the pig. In Proceedings of the VIth International Symposium on Digestive Physiology in Pigs, pp. 231-240 [WB Souffrant and H Hagemeister, editors]. Forschunginstitut fur die Biologie landwirtschaftlicher Nutztiere: European Association of Animal Production.

Cranwell PD \& Moughan PJ (1989) Biological limitations imposed by the digestive system to the growth performance of weaned pigs. In Manipulating Pig Production II. Proceedings of the Biennial Conference of the Australasian Pig Science Association, Albury, NSW, pp. 140-159 [JL Barnett and DP Hennessy, editors]. Werribee, NSW: Australasian Pig Science Association.

Ehrlein H \& Stockmann A (1998a) Absorption of nutrients is only slightly reduced by supplementing enteral formulas with viscous fiber in miniature pigs. Journal of Nutrition 128, 2446-2455.

Ehrlein H \& Stockmann A (1998b) Intestinal absorption of nutrients is not influenced by soy fiber and does not differ between oligomeric and polymeric enteral diets. Digestive Diseases and Sciences 43, 2099-2110.

Ellis PR, Dawoud FM \& Morris ER (1991) Blood glucose, plasma insulin and sensory responses to guar-containing wheat breads: effects of molecular weight and particle size of guar gum. British Journal of Nutrition 66, 363-379. 
Ellis PR, Roberts FG, Low AG \& Morgan LM (1995) The effect of high-molecular-weight guar gum on net apparent glucose absorption and net apparent insulin and gastric inhibitory polypeptide production in the growing pig: relationship to rheological changes in jejunal digesta. British Journal of Nutrition 74, 539-556.

Elsenhans B \& Caspary WF (2000) Food viscosity as determinant for adaptive growth responses in rat intestine: long-term feeding of different hydroxyethyl celluloses. British Journal of Nutrition 84, 39-48.

Etheridge RD, Seerley RW \& Huber TL (1984) The effect of diet on fecal moisture, osmolarity of fecal extracts, products of bacterial fermentation and loss of minerals in feces of weaned pigs. Journal of Animal Science 58, 1403-1411.

Gallaher DD, Hassel CA \& Lee KJ (1993) Relationships between viscosity of hydroxypropyl methylcellulose and plasma cholesterol in hamsters. Journal of Nutrition 123, 1732-1738.

Go JT, Harper RG, Sia CG, Teichberg S \& Wapnir RA (1994) Oral rehydration solutions: increased water and sodium absorption by addition of a viscosity-enhancing agent in a rat model of chronic osmotic diarrhoea. Journal of Pediatric Gastroenterology and Nutrition 19, 410-416.

Gohl B \& Gohl I (1977) The effect of viscous substances on the transit time of barley digesta in rats. Journal of the Science of Food and Agriculture 28, 911-915.

Gyles CL (1993) Escherichia coli. In Pathogenesis of Bacterial Infections in Animals, pp. 164-187 [CL Gyles and CO Thoen, editors]. Ames, IA: Iowa State University Press.

Hampson DJ, Woodward JM \& Connaughton ID (1993) Genetic analysis of Escherichia coli from porcine postweaning diarrhoea. Epidemiology and Infection 110, 575-581.

Hinton M, Hampson DJ, Hampson E \& Linton AH (1985) A comparison of the ecology of Escherichia coli in the intestine of healthy unweaned pigs and pigs after weaning. Journal of Applied Bacteriology 58, 471-477.

Ikegami S, Tsuchihashi F, Harada H, Tsuchihashi N, Nishide E \& Innami S (1990) Effect of viscous indigestible polysaccharides on pancreatic-biliary secretion and digestive organs in rats. Journal of Nutrition 12, 353-360.

Jensen BB (1998) The impact of feed additives on the microbial ecology of the gut in young pigs. Journal of Animal and Feed Sciences 7, 45-64.

Johnson IT \& Gee JM (1986) Gastrointestinal adaptation in response to soluble non-available polysaccharides in the rat. British Journal of Nutrition 55, 497-505.

Kenworthy R, Stubbs JM \& Syme G (1967) Ultrastructure of small-intestinal epithelium in weaned and unweaned pigs and pigs with post-weaning diarrhoea. Journal of Pathology and Bacteriology 93, 493-498.

Langhout DJ (1998) The role of the intestinal flora as affected by non-starch polysaccharides in broiler chicks. PhD Thesis, Wageningen Agricultural University.

Langhout DJ, Schutte JB, de Jong J, Sloetjes H, Vertsegen MWA \& Tamminga S (2000) Effect of viscosity on digestion of nutrients in conventional and germ-free chicks. British Journal of Nutrition 83, 533-540.

Larsen FM, Wilson MN \& Moughan PJ (1994) Dietary fiber viscosity and amino acid digestibility, proteolytic digestive enzyme activity and digestive organ weights in growing rats. Journal of Nutrition 124, 833-841.

MacAuliffe T \& McGinnis J (1971) Effect of antibiotic supplements to diets containing rye on chick growth. Poultry Science 50, 1130-1134.

McDonald DE, Pethick DW, Pluske JR \& Hampson DJ (1999) Adverse effects of soluble non-starch polysaccharide (guar gum) on piglet growth and experimental colibacillosis immediately after weaning. Research in Veterinary Science 67, 245-250.
McDonald DE, Pethick DW, Pluske JR, Mullan BP \& Hampson DJ (2000) Soluble non-starch polysaccharides from pearl barley exacerbate post-weaning colibacillosis. In Digestive Physiology in Pigs. Proceedings of the 8th Symposium, Uppsala, Sweden, [JE Lindberg and B Ogle, editors]. Oxford: CABI Publishing.

McRorie J, Brown S, Cooper R, Givaruangsawat S, Scruggs D \& Boring G (2000) Effects of dietary fibre and olestra on regional apparent viscosity and water content of digesta residue in porcine large intestine. Alimentary Pharmacology and Therapeutics 14, 471-477.

McRorie J, Pepple S \& Rudolph C (1998) Effects of fiber laxatives and calcium docusate on regional water content and viscosity of digesta in the large intestine of the pig. Digestive Diseases and Sciences 43, 738-745.

Misir R \& Marquardt RR (1978) Factors affecting rye (Secale cereale L.) utilization in growing chicks. 1 . The influence of rye level, ergot and penicillin supplementation. Canadian Journal of Animal Science 58, 391-701.

Morris ER (1992) Physico-chemical properties of food polysaccharides. In Dietary Fibre - A Component of Food. Nutritional Function in Health and Disease, pp. 41-55 [TF Schweizer and CA Edwards, editors]. London: Springer-Verlag.

Noblet J \& Etienne M (1987) Body composition, metabolic rate and utilization of milk nutrients in suckling piglets. Reproduction, Nutrition, Development 27, 829-839.

Okai DB, Aherne FX \& Hardin RT (1976) Effects of creep and starter composition on feed intake and performance of young pigs. Canadian Journal of Animal Science 56, 573-586.

Palmer NC \& Hulland TJ (1965) Factors predisposing to the development of coliform gastroenteritis in weaned pigs. Canadian Veterinary Journal 6, 310-316.

Pluske JR (1993) Psychological and nutritional stress in pigs at weaning: production parameters, the stress response, and histology and biochemistry of the small intestine. PhD Thesis, The University of Western Australia.

Pluske JR, Siba PM, Pethick DW, Durmic A, Mullan BP \& Hampson DJ (1996) The incidence of swine dysentery in pigs can be reduced by feeding diets that limit the amount of fermentable substrate entering the large intestine. Journal of Nutrition 126, 2920-2933.

Rainbird AL (1986) Effect of guar gum on gastric emptying of test meals of varying energy content in growing pigs. British Journal of Nutrition 55, 99-109.

Rainbird AL \& Low AG (1986a) Effect of various types of dietary fibre on gastric emptying in growing pigs. British Journal of Nutrition 55, 111-121.

Rainbird AL \& Low AG (1986b) Effect of guar gum on gastric emptying in growing pigs. British Journal of Nutrition 55, 87-98.

Rainbird AL, Low AG \& Zebrowska T (1984) Effect of guar gum on glucose and water absorption from isolated loops of jejunum in conscious growing pigs. British Journal of Nutrition 52, 489-498.

Rossi S, Bonferoni MC, Ferrari F, Bertoni M \& Caramell C (1996) Characterization of mucin interaction with three viscosity grades of sodium carboxymethylcellulose. Comparison between rheological and tensile testing. European Journal of Pharmaceutical Sciences 4, 189-196.

Smits CH, Veldman A, Verkade HJ \& Beynen AC (1998) The inhibitory effect of carboxymethylcellulose with high viscosity on lipid absorption in broiler chickens coincides with reduced bile salt concentration and raised microbial numbers in the small intestine. Poultry Science 77, 1534-1539.

Smits CHM, Veldman A, Verstegen MWA \& Beynen AC (1997) Dietary carboxymethylcellulose with high instead of low viscosity reduces macronutrient digestion in broiler chickens. Journal of Nutrition 127, 483-487. 
Thomlinson JR \& Lawrence TL (1981) Dietary manipulation of gastric $\mathrm{pH}$ in the prophylaxis of enteric disease in weaned pigs: some field observations. Veterinary Record 109, $120-122$.

Tomlin J, Read NW, Edwards CA \& Duerdan BI (1986) The degradation of guar gum by a faecal incubation system. British Journal of Nutrition 55, 481-486.

Topping DL, Oakenfull D, Trimble RP \& Illman RJ (1988) A viscous fibre (methylcellulose) lowers blood glucose and plasma triacylglycerols and increases liver glycogen independently of volatile fatty acid production in the rat. British Journal of Nutrition 59, 21-30.

van der Klis JD, van Voorst A \& van Cruyningen C (1993) Effect of a soluble polysaccharide (carboxy methyl cellulose) on the physico-chemical conditions in the gastrointestinal tract of broilers. British Poultry Science 34, 971-983.

Wapnir RA, Wingertzahn MA \& Teichberg S (1997) Cellulose derivatives and intestinal absorption of water and electrolytes: potential role in oral rehydration solutions. Proceedings of the Society for Experimental Biology and Medicine 215, $275-280$.

Wyatt GM, Horn N, Gee JM \& Johnson IT (1988) Intestinal microflora and gastrointestinal adaptation in the rat in response to non-digestible dietary polysaccharides. British Journal of Nutrition 60, 197-207. 